\title{
ATMOSPHERIC PRESSURE GLOW DISCHARGE IN AIR
}

\author{
R. B. Tyata ${ }^{1,2}$, D. P. Subedi ${ }^{1}$, C. S. Wong ${ }^{3}$ \\ ${ }^{1}$ Department of Natural Science, Kathmandu University, Dhulikhel, Nepal \\ ${ }^{2}$ Department of Electrical Engineering, Khwopa College of Engineering, Libali-2, Bhaktapur, Nepal \\ ${ }^{3}$ Plasma Research Laboratory, Physics Department, University of Malaya, 50603 Kuala Lumpur, Malaysia
}

\begin{abstract}
In this study, an atmospheric pressure glow discharge (APGD) in air using $50 \mathrm{~Hz}$ power supply was experimentally investigated by means of electrical characterization. The discharge has been generated in a specially designed hemispherical-plane electrode system. The main objective of the study was to identify the conditions to generate AC glow at atmospheric pressure air using $50 \mathrm{~Hz}$ power supply. The mode of discharge was characterized by observing the number of current pulses per half cycle in the current waveform of the discharge for different values of applied voltage for different electrode spacing. It was found that with $3 \mathrm{~mm}$ gap and $18.75 \mathrm{kV}$ of applied voltage, the current waveforms consist of a single pulse per half cycle indicating the formation of AC glow discharge. An attempt to study the effect of dielectric on the mode of the discharge was also made by using three types of materials namely Polycarbonate, Polyethylene and Glass as barrier between the electrodes.
\end{abstract}

Keywords: Electrical discharge, APGD, Asymmetric electrode, Without dielectric, Air

\section{Introduction}

Dielectric barrier discharge (DBD) and APGD are well-known plasma sources for the generation of nonthermal plasma. When the local electric field strength in the gas gap reaches the ignition level, then breakdown starts at many points followed by the development of filaments. Since large numbers of such filaments are induced and randomly distributed in space and time, it results in an average uniform distribution of microdischarges over dielectric surface (Eliasson and Kogleschatz, 1991). Appearance of APGD mainly depends on the experimental conditions such as discharge gas, gas pressure, inter-electrode gap, dielectric properties of the barrier and the nature of the applied voltage (Rahel and Sherman, 2005, Gherardi and Massines, 2001, Massines et al, 1998).

As APGDs have great advantages - they do not need expensive vacuum system and possess the

*Corresponding author: R. B. Tyata,

Department of Natural Science, Kathmandu University, Dhulikhel, Nepal

Contact:977-9841432100_Email: rbtyata@yahoo.com (Received: 2011 Nov 3 Accepted: 2011 Nov 29)

JScE Vol. 1, Falgun 2068 capability to produce agents, such as reactive species, charged particles, and UV radiation - they find widespread applications in treatment of polymers (Subedi et al, 2008), plasma coating (Hubi ${ }_{i}$ cka, 2002), cleaning and activation of substrates (Dumitrascu et al, 2002), thin film deposition (Jiang et al, 2001), water treatment (Subedi et al, 2009), sterilization, cancer cell treatment, dental treatment, surface modification of biocompatible materials (Laroussi, 2005, Fridman et al, 2007).

Various kinds of APGD sources such as the atmospheric pressure plasma jet, the dielectric barrier discharges, the atmospheric pressure plasma needle, and the cold plasma torch have been developed, and their generation has been achieved over a very wide spectrum from DC through kilohertz and megahertz to microwave, and their electrodes are either metallic or coated with a dielectric layer (Iza et al, 2008, Stoffels et al, 2003, Laroussi and Akan, 2007, Leveille and Coulombe, 2005). 
In recent years, several researchers have tried to obtain the homogeneous dielectric barrier discharge and glow discharge at atmospheric pressure using different working gases such as neon, helium, argon, nitrogen, air and their mixture with other gases. Okazaki et al (1993) studied the stabilization of homogeneous DBD at atmospheric pressure with 50 $\mathrm{Hz}$ power supply in air, argon, oxygen and nitrogen. Garamond and El-zeer (2009) gave remarkable result of homogeneous DBD at atmospheric pressure with $50 \mathrm{~Hz}$ power supply in air using barrier of porous alumina ceramic. In order to improve the stability and the working domain of homogeneous discharges, Topper et al. (2000) studied the spatial and temporal behavior. Kanazawa et al. (1998) purposed stability of homogeneous DBD in helium gas with certain gas mixture with the frequency $10-50 \mathrm{kHz}$. Trunec et al (2001) showed that atmospheric pressure glow discharge (APGD) can also be generated using high frequency $10 \mathrm{kHz}$ power supply in pure neon. Luo et al (2010) also investigated homogeneous barrier discharge in nitrogen at atmospheric pressure by means of electrical measurement, fast photography and time resolved spectroscopy.

In this report, we present electrical characterization of a glow discharge produced in an especially designed parabolic-plane electrode system without the use of dielectric barrier.

\section{Experimental Setup}

The schematic diagram of experimental arrangement used to study the atmospheric pressure glow discharge (APGD) is shown in Fig 1.

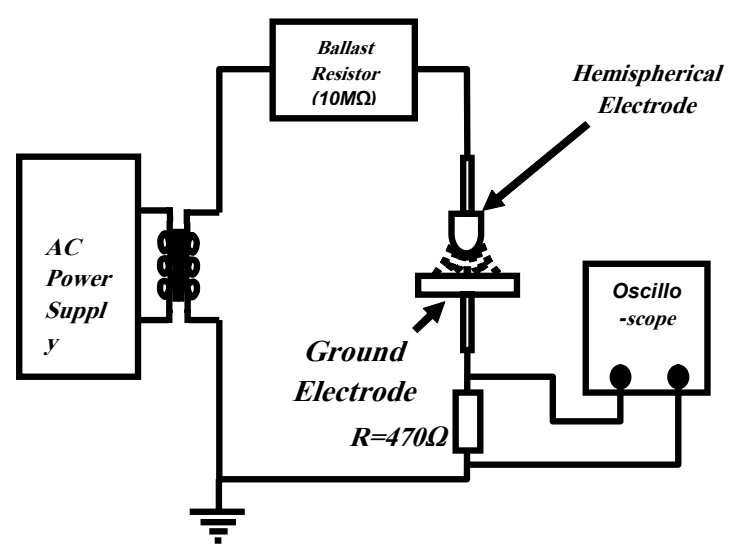

Fig.1. Schematic diagram of experimental setup
The discharge was generated between two asymmetric electrodes. The upper one is parabolic in shape with $3.15 \mathrm{~cm}$ diameter and $1.5 \mathrm{~cm}$ height. The lower electrode is circular in shape with 5.05 $\mathrm{cm}$ diameter and $1.02 \mathrm{~cm}$ thickness made of brass. A high voltage $50 \mathrm{~Hz}$ AC power supply was connected across the electrode through a ballast resistor of resistance $10 \mathrm{M} \&$ ! Ohm. The interelectrode gap was varied from $1 \mathrm{~mm}$ to $3 \mathrm{~mm}$. Electrical characterization was made with the help of a high voltage probe using Tektronix TDS2002 digital oscilloscope.

\section{Result and Discussion}

Fig 2(a-f) and Fig 3(a-f) show the current waveforms and Fig 2(g-h) and Fig 3(g-h) the images of an atmospheric pressure discharge in air without using dielectric medium between the electrodes with a high voltage $(0-16 \mathrm{kV})$ power supply operating at frequency $50 \mathrm{~Hz}$. As shown in Fig 2(a-f), the discharge in hemispherical plane electrodes system with $1 \mathrm{~mm}$ gap consisted of number of spikes in current waveform. Initially, these spikes were found to increase gradually and then decrease when the applied voltage was varied from $3.9 \mathrm{kV}$ from $8.6 \mathrm{kV}$. It is evident that it is possible to count the number of current pulses per half cycle by the observation of the waveforms of the discharge. For the discharge with 2mm gap as shown in Fig 3(a-f), it is interesting to note that the spikes in the current waveform tend to fuse together resulting in a single spike in the waveform. The relation between applied voltage and number of spikes as shown in Fig 4(a-b) and Fig 4(cd) show the typical current waveforms of APGD without dielectric and its corresponding images in air applying different voltage $6.25 \mathrm{kV}$ and $18.75 \mathrm{kV}$ at frequency $50 \mathrm{~Hz}$. The current waveform of the discharge in 3mm of electrode spacing exhibits only one current pulse per half cycle. The relation between applied voltage verses number of spikes is shown in Fig 5. This relation indicates that when applied voltage is gradually increased from lower voltage, the number of spikes is gradually increased and after attaining maximum value, the number of spikes is decreased. When the applied voltage was gradually decreased from higher voltage, the numbers of spikes were meagre into single waveform which is clearly 
shown in Fig 6. Fig 7(a-f) clearly indicate that current waveforms and the images of dielectric barrier discharge using different dielectric materials namely

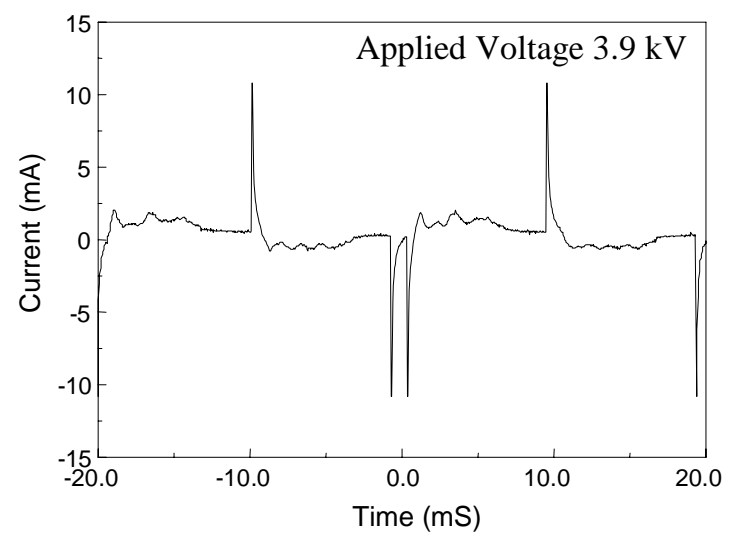

a) Current waveform of discharge with 1-2 spikes per half cycle

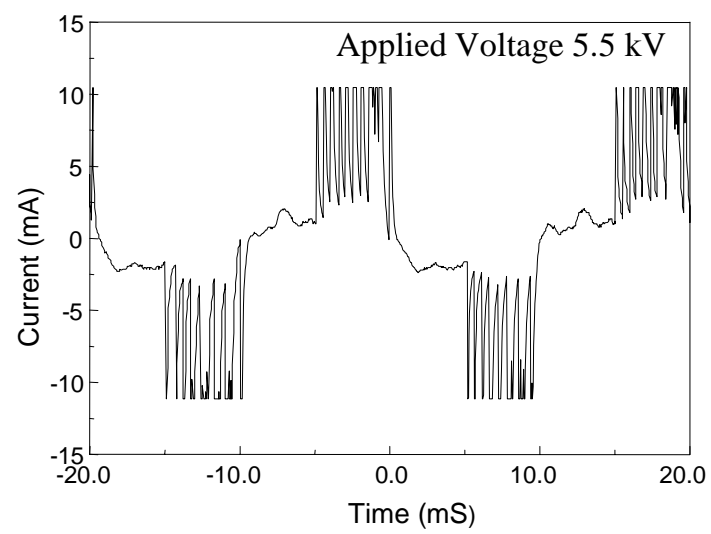

c) Current waveform of discharge with 7-8 spikes per half cycle

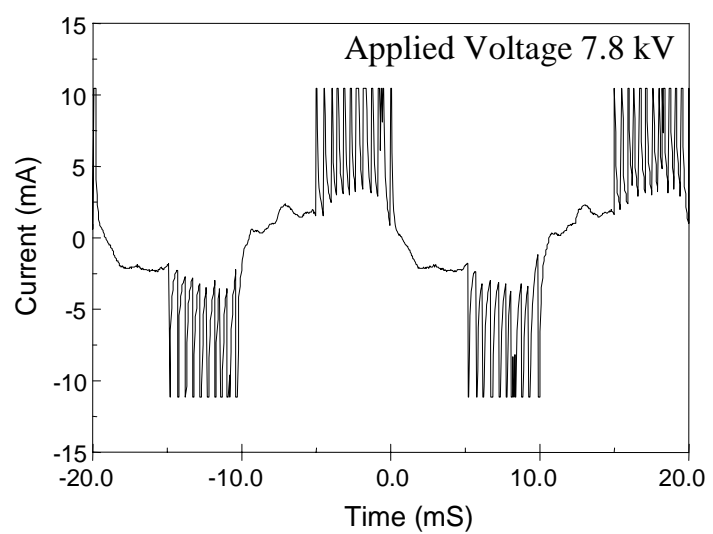

e) Current waveform of discharge with 8-9 spikes per half cycle
Glass $(2.5 \mathrm{~mm}), \mathrm{PC}(2 \mathrm{~mm})$ and PE $(0.16 \mathrm{~m})$ consist of several filaments per-half cycle indicating a filamentary mode of the discharge.

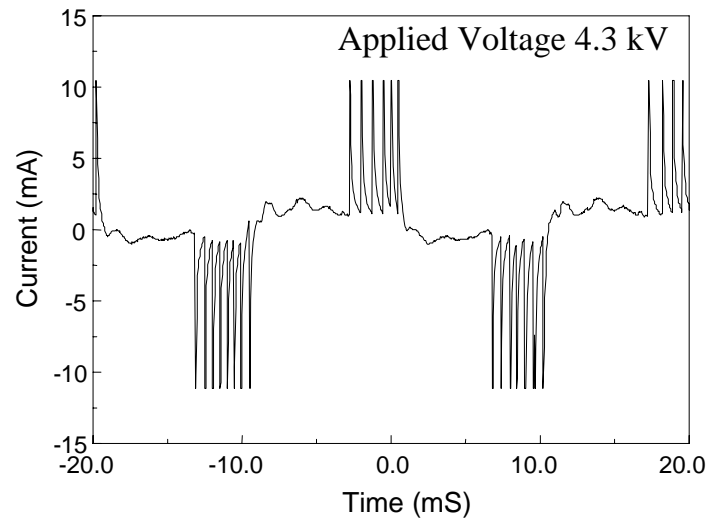

b) Current waveform of discharge with 6-7 spikes per half cycle

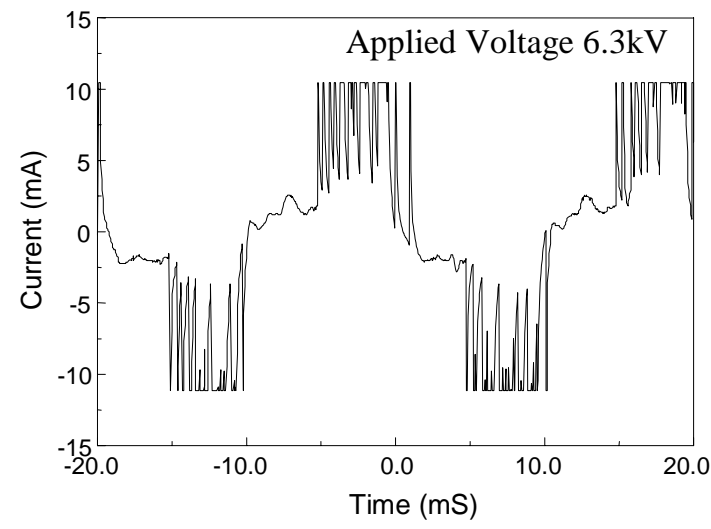

d) Current waveform of discharge with 8-9 spikes per half cycle

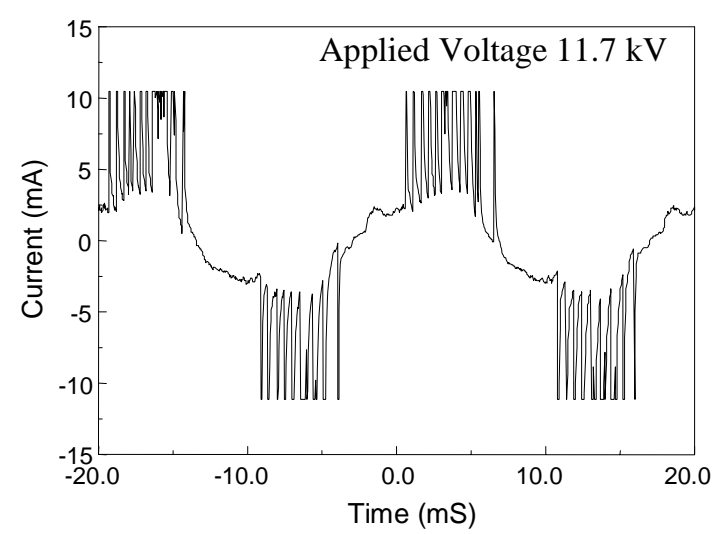

f) Current waveform of discharge with 9-10 spikes per half cycle 


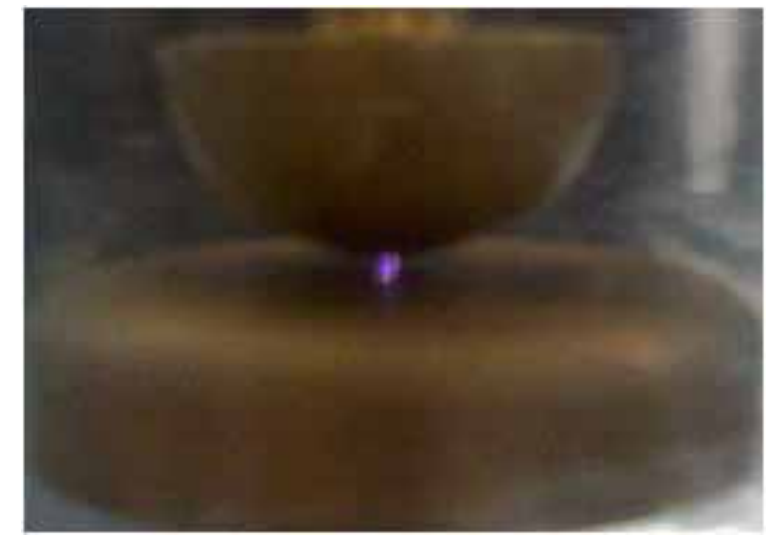

g) Image of discharge using applied voltage $3.9 \mathrm{kV}$

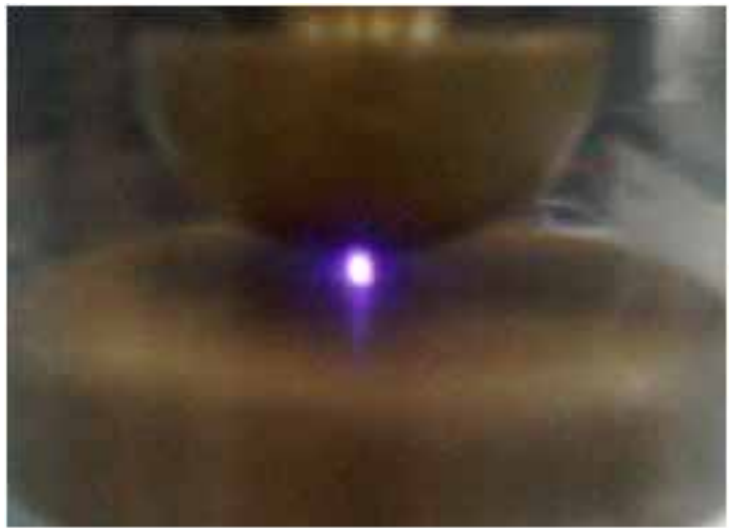

g) Image of discharge using applied voltage $3.9 \mathrm{kV}$

Fig.2. Current waveforms of the discharge produced at $50 \mathrm{~Hz}$ with $1 \mathrm{~mm}$ inter-electrode gap without dielectric barrier and images of discharge

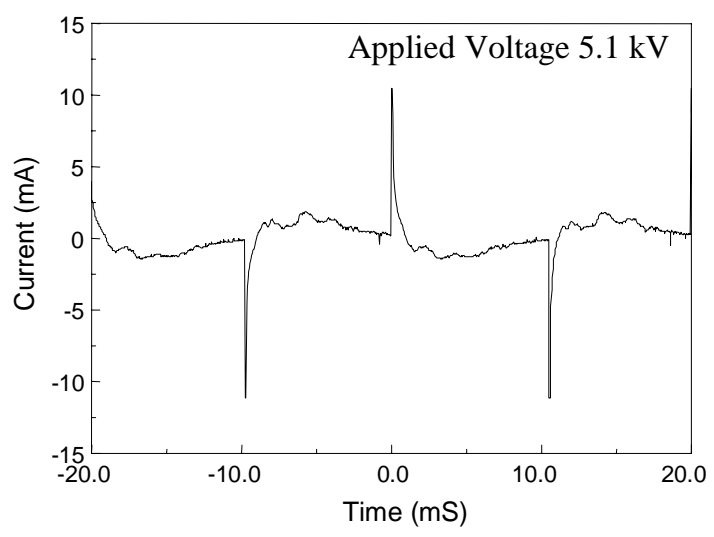

a) Current waveform of discharge with one spike per half cycle

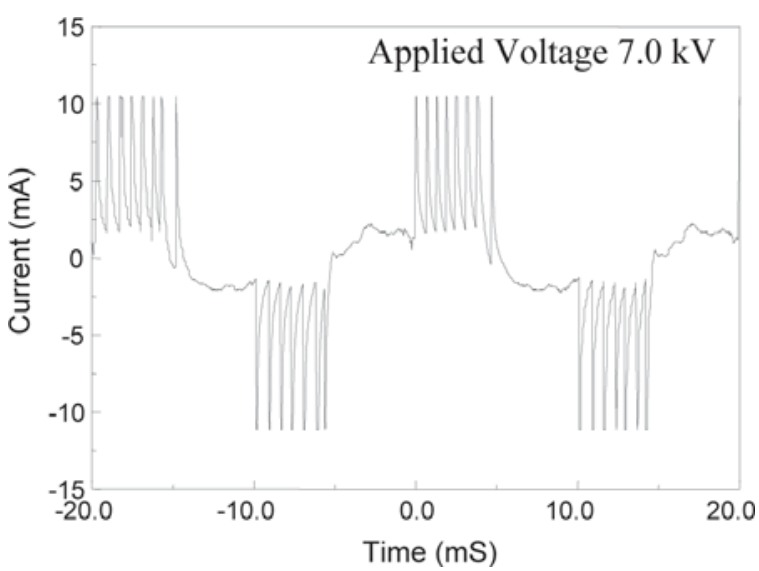

c) Current waveform of discharge with 7-8 spikes per half cycle

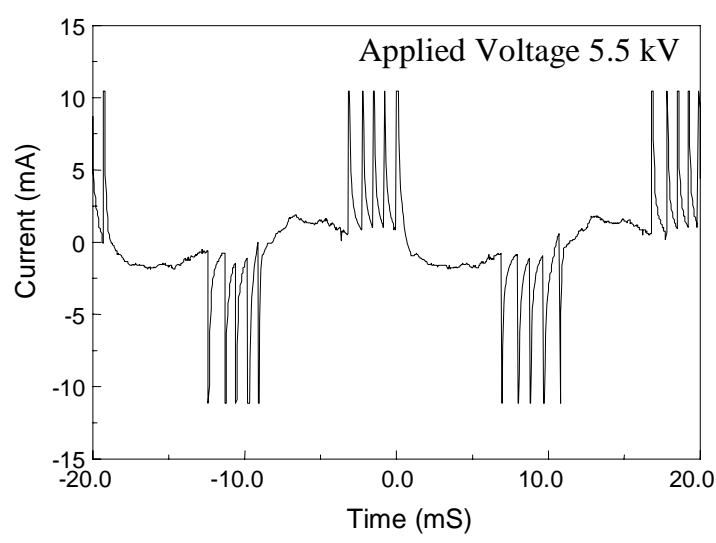

b) Current waveform of discharge with 5 spikes per half cycle

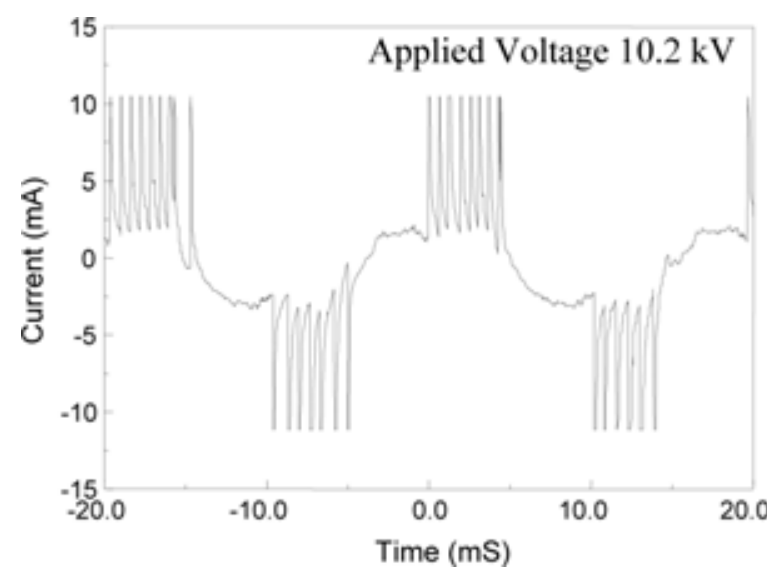

d) Current waveform of discharge with 6-7 spikes per half cycle 


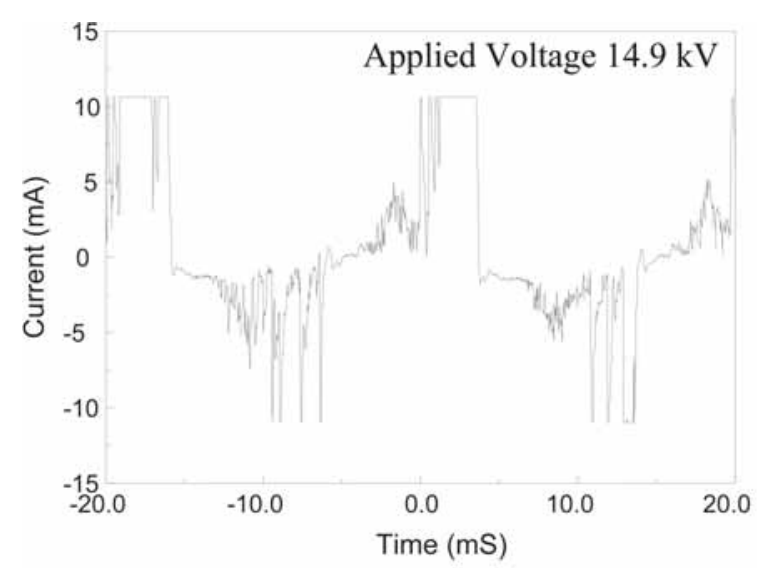

e) Current waveform of discharge with 3-4 spikes per half cycle

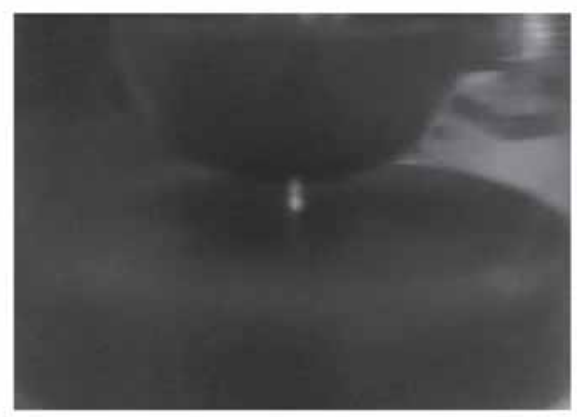

g) Image of discharge using applied voltage $5.1 \mathrm{kV}$

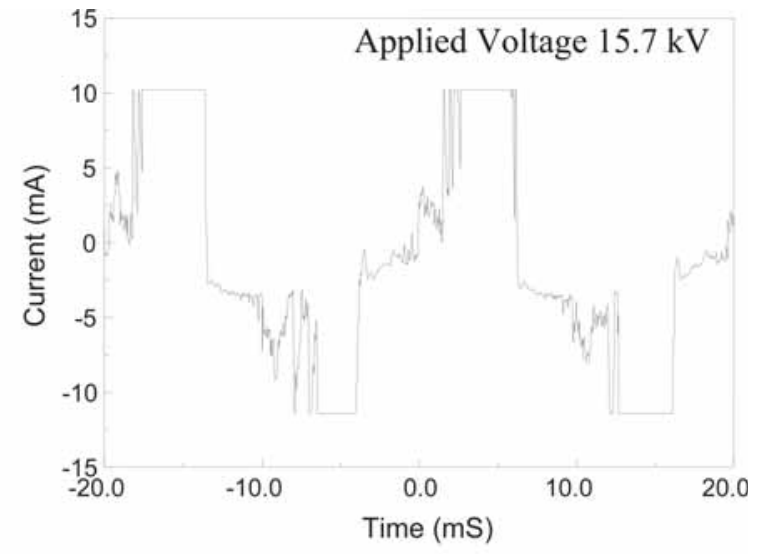

f) Current waveform of discharge with 2-3 spikes per half cycle

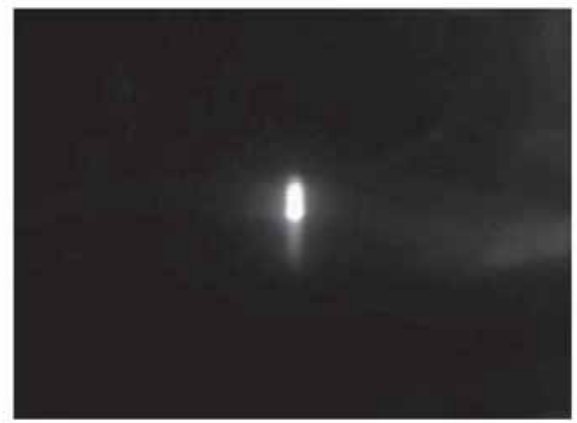

h) Image of discharge using applied voltage $15.7 \mathrm{kV}$

Fig.3. Current waveforms of the discharge produced at $50 \mathrm{~Hz}$ with $2 \mathrm{~mm}$ inter-electrode gap without dielectric barrier and images of discharge

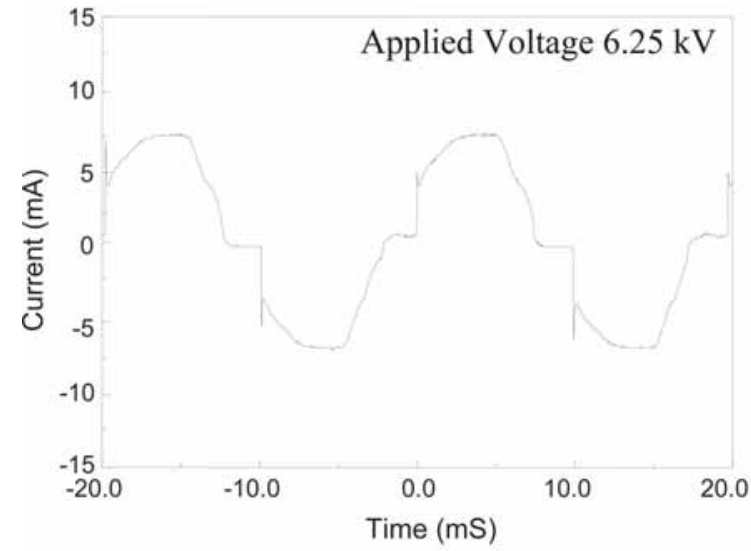

a) Current waveform of APGD with one spike per half cycle

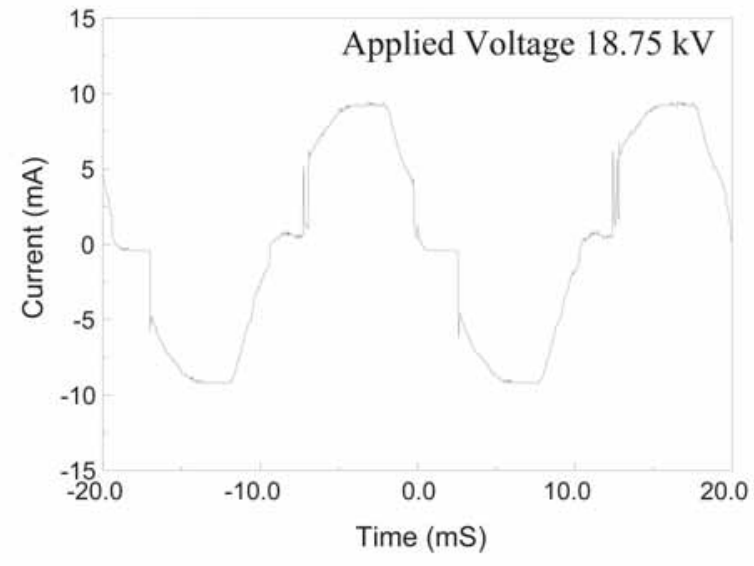

b) Current waveform of APGD with one spike per half cycle 


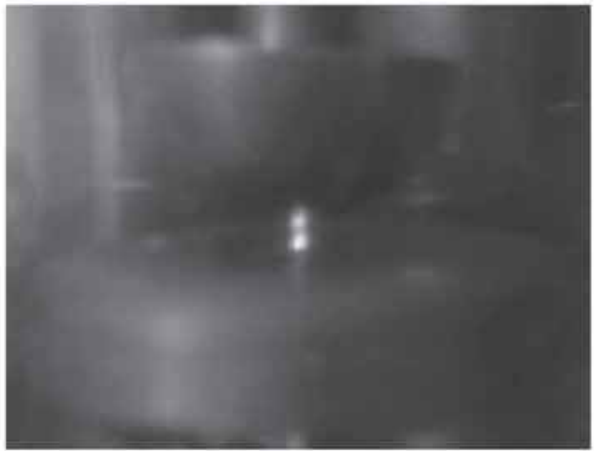

c) Image of APGD using applied voltage $6.25 \mathrm{kV}$

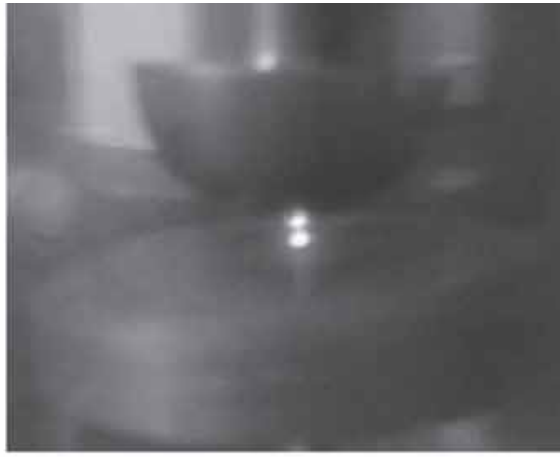

d) Image of APGD using applied voltage $18.75 \mathrm{kV}$

Fig.4. Current waveforms of the APGD produced at $50 \mathrm{~Hz}$ with $3 \mathrm{~mm}$ inter-electrode gap without dielectric barrier and the images of APGD
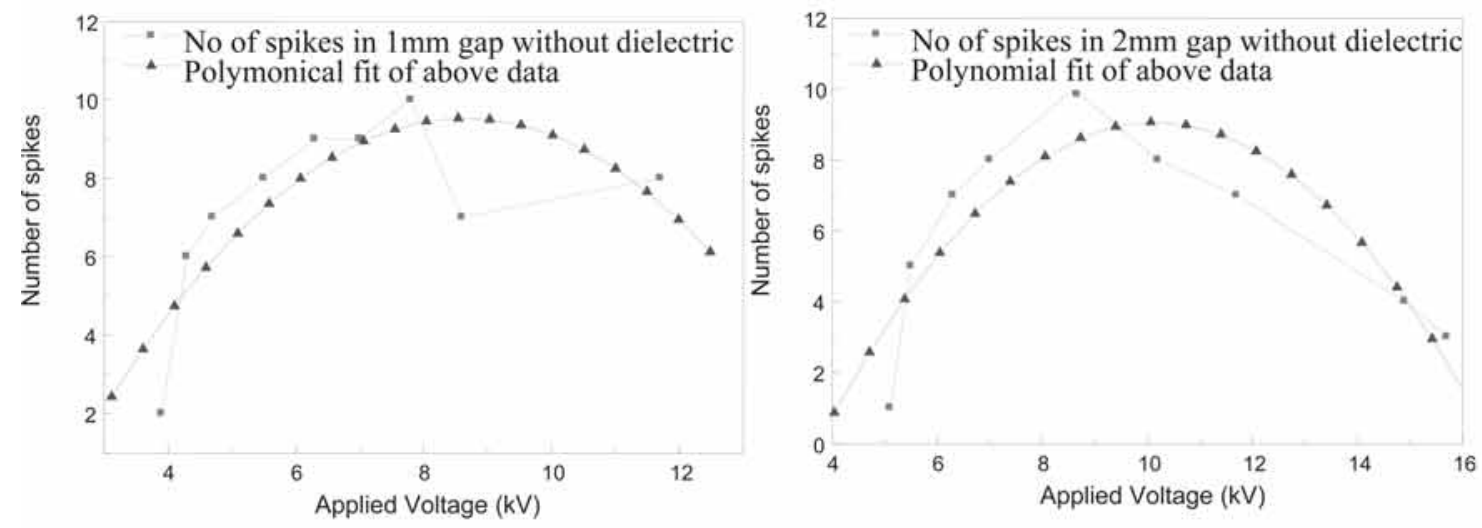

Fig.5. The relation between applied voltage and number of filaments or spikes.

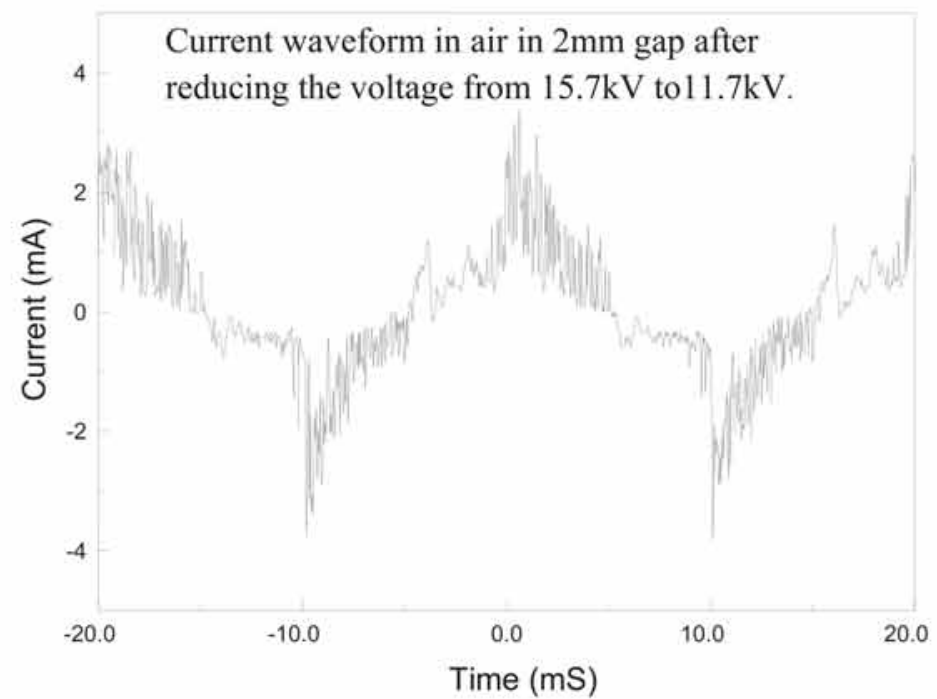

Fig.6. Current Waveform of discharge in air without dielectric after decreasing the applied voltage. 


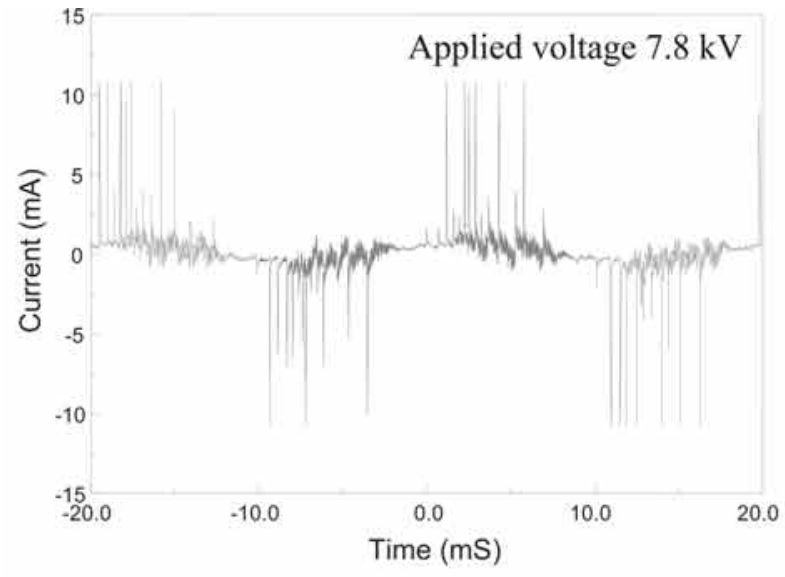

a) Current waveform of DBD in air with dielectric of Glass $(2.5 \mathrm{~mm})$ in $2 \mathrm{~mm}$ gap

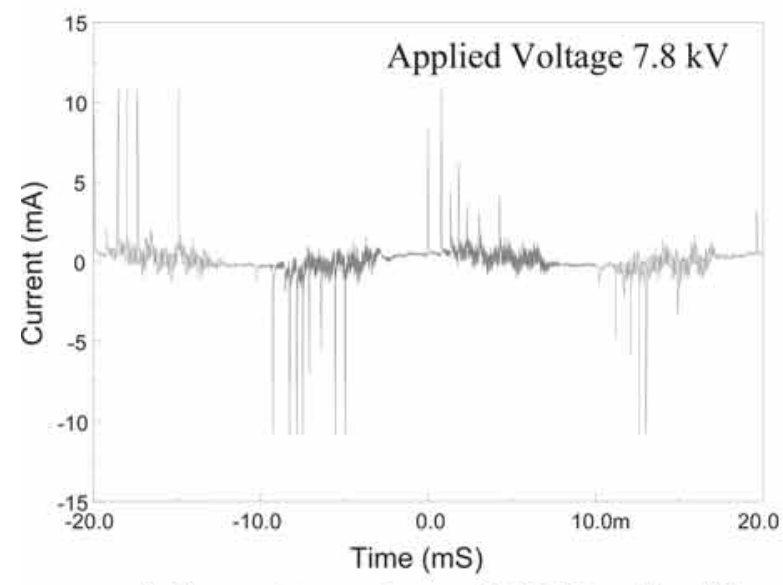

c) Current waveform of DBD in air with dielectric of Polycarbonate $(2 \mathrm{~mm})$ in $2 \mathrm{~mm}$ gap

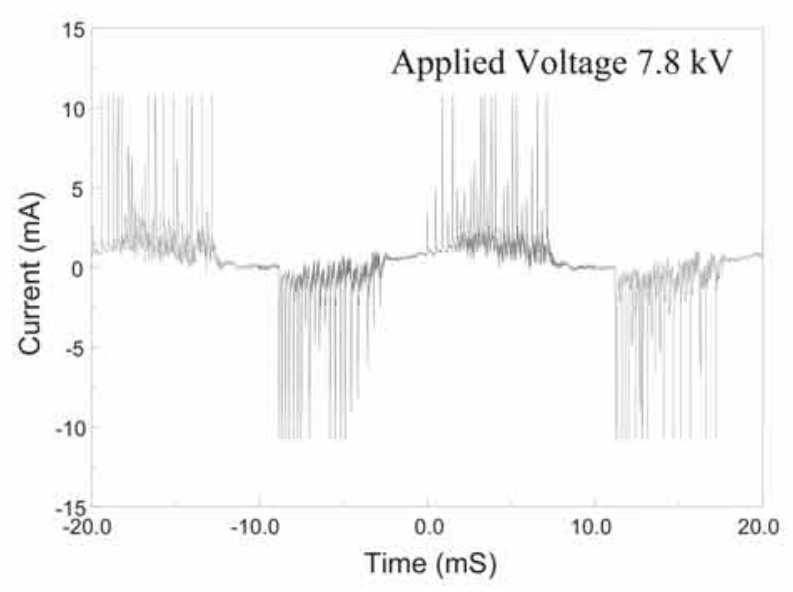

e) Current waveform of DBD in air with dielectric of Polyethylene $(0.16 \mathrm{~mm})$ in $2 \mathrm{~mm}$ gap

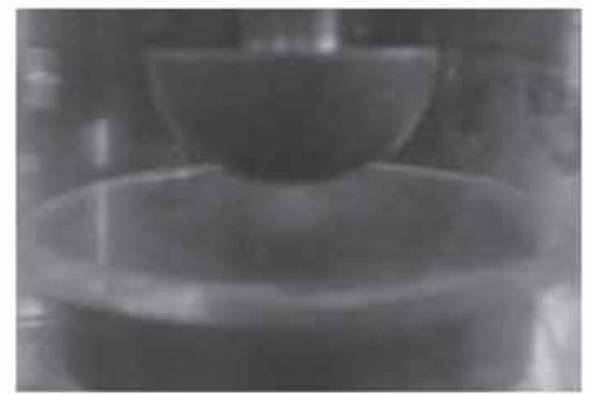

b) The image of DBD in air with dielectric of Glass $(2.5 \mathrm{~mm})$ in $2 \mathrm{~mm}$ gap using applied voltage $7.8 \mathrm{kV}$

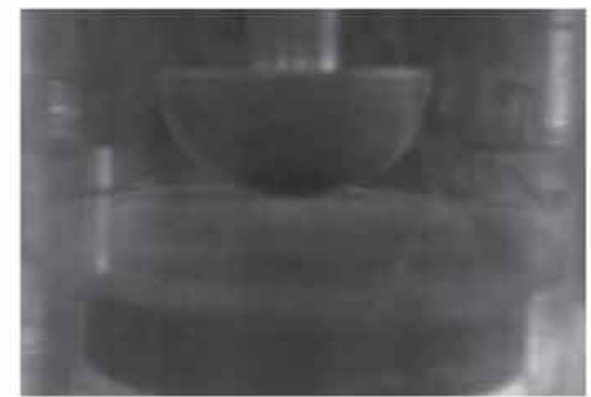

d) The image of DBD in air with dielectric of Polycarbonate $(2 \mathrm{~mm})$ in $2 \mathrm{~mm}$ gap using applied voltage $7.8 \mathrm{kV}$

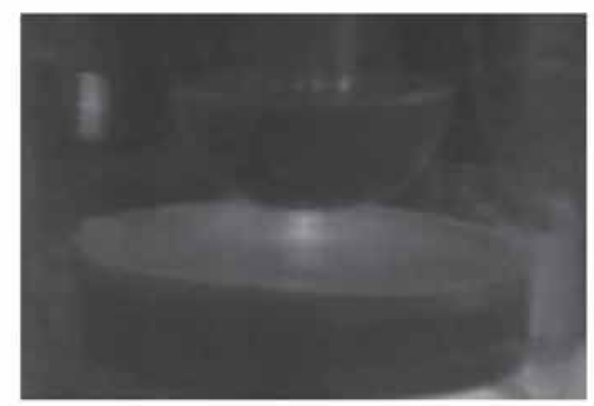

f) The image of DBD in air with dielectric of Polyethylene $(0.16 \mathrm{~mm})$ in $2 \mathrm{~mm}$ gap using applied voltage $7.8 \mathrm{kV}$

Fig.7. Current Waveforms and images of discharge in air with different dielectric in $2 \mathbf{~ m m}$ gap using applied voltage $7.8 \mathrm{kV}$ 


\section{Conclusion}

A filamentary mode of discharge in 1-2mm gap could be generated in air with $50 \mathrm{~Hz}$ power supply even without using dielectric medium. Atmospheric pressure glow discharge in air could be generated using $50 \mathrm{~Hz}$ power supply without dielectric barrier for specific gap of 3mm. Number of peaks obtained in discharge current depends on applied voltage and electrode gap. The effect of dielectric material on the quality of discharge could be detected by electrical signal. Electrical signals could be helpful in understanding the transition of filamentary mode of the discharge into glow mode.

\section{Acknowledgement}

This work was supported by the University Grants Commission (UGC), Sanothimi, Bhaktapur, Nepal.

\section{References}

[1] Eliasson, B., and Kogleschatz, U., 1991. Non-equilibrium volume plasma chemical processing. IEEE Trans. Plasma Sci., No. 19, pp 1063-77.

[2] Rahel, J., and Sherman, D. M., 2005. The transition from a filamentary dielectric barrier discharge to a diffuse barrier discharge in air at atmospheric pressure. J. Phys. D: Appl. Phys., No. 38, pp 547-54.

[3] Gherardi, N., and Massines, F., 2001. Mechanisms controlling the transition from glow silent discharge to streamer discharge in nitrogen. IEEE Trans. Plasma Sci., No. 29, pp 536-44.

[4] Massines, F., Rabehi, A., Decomps, P., Gadri, R. B., Segur, P., and Mayoux, C., 1998. Experimental and theoretical study of glow discharge at atmospheric pressure controlled by dielectric barrier. J. Appl. Phys. No 83, pp 2950-57.

[5] Subedi, D. P., Madhup, D. K., Laghu, A. K., Joshi, U. M. and Tyata, R. B., 2008. Hydrophilization of low density polyethylene by dielectric barrier discharge. Journal of Science and Technology in the Tropics, No. 4, pp 73-77.

[6] Hubi icka, Z., 2002. Barrier-torch discharge plasma source for surface treatment technology at atmospheric pressure. Plasma Sources Sci. Technol., No. 11, pp 195-202.

[7] Dumitrascu, N., Borcia, G., Apetroaei, N., and Popa, G., 2002. Roughness surface modification of surfaces treated by a pulsed dielectric barrier discharge. Plasma Sources Sci. Technol., No. 11, pp 127-134.

[8] Jiang, N., Qian, S. F., Wang, L., Zhang, H. X., Localized material growth by a dielectric barrier discharge. Thin Solid Films, No. 390, pp 119-22.
[9] Subedi, D. P., Tyata, R. B., Khadgi, A. and Wong, C. S., 2009. Treatment of water by dielectric barrier discharge. Journal of Sci. and Technol. in the Tropics, No 5, pp 117-23.

[10] Laroussi, M., 2005. Low temperature plasma-based sterilization: overview and state-of-the art. Plasma Process Polym., No. 2, pp 391-400.

[11] Fridman, G., Shereshevsky, A., Jost, M. M., Brooks, A. D., Fridman, A., Gutso,l A., Vasilets, V. and Friedman, G., 2007. Floating electrode dielectric barrier discharge plasma in air promoting apoptotic behavior in melanoma skin cancer cell lines. Plasma Chem. Plasma Process, No. 27, pp 163-76.

[12] Iza, F., Kim, G. J., Lee, S. M., Lee, J. K., Walsh, J. L., Zhang, Y. T., and Kong, M. G., 2008. Microplasmas: sources, particle kinetics, and biomedical applications. Plasma Process Polym., No. 5, pp 322-44.

[13] Laroussi, M., and Akan, T., 2007. Arc-free atmospheric pressure cold plasma jets: a review. Plasma Process Polym., No. 4, pp 777-88.

[14] Stoffels, E., Kieft, I. E., and Sladek, R. E. J., 2003. Superficial treatment of mammalian cells using plasma needle. J. Phys. D: Appl. Phys., No. 36, p 2908.

[15] Leveille, V., and Coulombe, S., 2005. Design and preliminary characterization of a miniature pulsed RF APGD torch with downstream injection of the source of reactive species. Plasma Sources Sci. Technol., No. 14, p 467.

[16] Okazaki, S., Kogoma, M., Uehara, M., and Kimura, Y., 1993. Appearance of stable glow discharge in air, argon, oxygen and nitrogen at atmospheric pressure using a $50 \mathrm{~Hz}$ source. J. Phys. D: Appl. Phys., No. 26, pp 889-92.

[17] Garamoon, A. A. and El-zeer, D. M., 2009. Atmospheric pressure glow discharge plasma in air at frequency $50 \mathrm{~Hz}$. Plasma Sources Sci. Technol., No. 18, (045006).

[18] Toppe, J., Lindmayer, M., and Juttner, B., 2000. Optical and electrical measurements of homogeneous barrier discharges at atmospheric pressure. XIII international Conf. on Gas Discharge and their Application, Glasgow, Scotland. No. 03.

[19] Kanazawa S, Kogoma M, Moriwaki T and Okazai S. 1988. Stable glow plasma at atmospheric pressure. J. Phys. D: Appl. Phys., No. 21, pp 838-40

[20] Trunec, D., Brablec, A., and Buchta, J.,2001. Atmospheric pressure glow discharge in neon. J. Phys. D: Appl. Phys., No. 34, pp 1697-99.

[21] Luo, H., Liang, Z., Wang, X., Gaun, Z., and Liming, W., 2010. Homogeneous dielectric barrier discharge in nitrogen at atmospheric pressure. J. Phys. D: Appl. Phys., No. 43, ( 155201). 